\title{
The economics of clinical negligence reform in England*
}

\author{
Paul Fenn \\ University of Nottingham Business School
}

Alastair Gray

Health Economics Research Centre, University of Oxford

Neil Rickman ${ }^{\dagger}$

Department of Economics, University of Surrey and CEPR

14 December 2003

\footnotetext{
* Acknowledgements: We are grateful to the Department of Health for funding some of the research reported in this paper; the Chief Medical Officer's Advisory Group for comments on our work; the NHS Litigation Authority for providing data; Howard Carrier and Rob Young for research assistance; and to the Editor and two anonymous referees for valuable comments. The views expressed here are those of the authors alone, who are also responsible for any errors.

${ }^{\dagger}$ Corresponding author: Department of Economics, University of Surrey, Guildford GU2 7XH; Telephone: +44 (0)1483 689320; Fax: +44 (0)1483 689548; E-mail: n.rickman@surrey.ac.uk.
} 


\begin{abstract}
In Britain, the NHS spends millions of pounds a year compensating patients injured during medical treatment. As in many other jurisdictions, compensation is paid if the patient can demonstrate that treatment was supplied negligently. However, concern over the cost, effectiveness and administrative efficiency of this approach has led jurisdictions like Sweden, New Zealand and some US states to alter the basis for compensation, and the Department of Health has now published proposals for reform in England. We present new research to assess the current approach in England and, for the first time, to provide costings for some key alternatives to have featured in the latest policy debate. We also draw some lessons for reform from international experience.
\end{abstract}

Keywords: Health, Compensation, Negligence, No-fault

JEL classification: I18, K13 
Sustaining an injury related to medical care can have serious economic and health consequences, and such injuries are a growing concern in many countries due to a perception that the costs they give rise to are rapidly increasing. Public policy in this area can be regarded as having to address two key objectives: providing compensation to those who have suffered injuries, and providing incentives to practitioners to supply an appropriate standard of care. However, different countries have adopted widely varying strategies in pursuit of these objectives, and in particular have adopted very different approaches to the question of liability for injury.

In the UK, victims of medical injuries can claim compensation by filing a legal claim against the alleged perpetrator, such as a hospital or individual practitioner. In order to secure an award of damages, the claimant must prove that the defendant is at fault for the injuries cited, or, in the current UK terminology, that the tort of clinical negligence has occurred. This negligence liability approach, however, is not found in all jurisdictions. For example, in Sweden, New Zealand and some American states, it is sufficient mainly to prove that the defendant caused the injuries in order to receive damages. Because it is not necessary to prove negligence, these schemes are often termed 'no-fault' schemes, and are typically thought to have lower administrative costs due to the reduced burden of proof. ${ }^{1}$ These contrasting approaches to medical injury have many distributional and other consequences: for example, under negligence liability, if injurers take efficient care the victims bear all losses, whereas under no-fault the injurers bear all losses irrespective of their care decision. However, research attention has focused on two particular areas of interest: first, assessing the respective cost and efficiency characteristics of negligence liability and no-fault schemes and, second, seeing whether other composite models can be created; for instance, models in which some element of fault must be proven, but in which the cost, delay and complexity involved in obtaining compensation are reduced by streamlining legal procedures and/or transferring liability from individual physicians to their employers.

\footnotetext{
${ }^{1}$ Such schemes exist in the UK for criminal injuries compensation and some employment tribunals. They can be found in Europe, the US, Canada and Australasia, covering compensation for, e.g., automobile accidents and workers' compensation - as well as clinical injuries.
} 
The UK's fault-based approach to compensation has received significant criticism for a number of years, and has been accused of failing either to provide fair compensation or to create incentives for deterrence. Most recently, the National Audit Office (NAO, 2001), a major public inquiry (Kennedy, 2001) and the House of Commons Public Accounts Committee (PAC, 2002) have each proposed radical reform. The principal charges are that the system is costly to the NHS, imposes long delays on patients seeking redress, is administratively inefficient (in that the legal and administrative costs of cases regularly exceed the value of the damages at stake), and engenders a culture of secrecy and cover-up in which colleagues are unwilling to "blow the whistle" on bad practice and is therefore inimical to improved standards of care. In support of these charges, it has been noted that in 2000/01 total NHS provisions for future settlements of negligence claims stood at $£ 4.4 \mathrm{bn}$; that the average time to resolution of the 23,000 cases outstanding at the end of March 2000 (excluding the longest, most complex, cases) was over five years; and that in $65 \%$ of settlements below $£ 50,000$, legal costs exceeded damages. ${ }^{2}$ Recognising these concerns, the Secretary of State for Health established an Advisory Group in 2001 to examine possible reforms, and in June 2003 a set of proposals was published for consultation (DoH, 2003). Whilst it rejects a general move to no-fault compensation, a stated aim of this consultation document is to "move the role of tort from its current central position to the outer perimeter of the NHS." (Chapter 8, paragraph 10). In its place would be a "Redress Scheme" containing a fast procedure for resolving "small claims” (those with value below £30,000) - ultimately involving a relaxed standard of care - and a no-fault procedure for compensating birth-related neurological injuries (typically those injuries with the highest cost and complexity). Under these proposals, a person would retain the right to sue through the courts but (except for neurologically impaired babies) with a presumption that they had first applied to the NHS Redress Scheme. Those accepting packages of care (where possible to be provided by the NHS) and compensation under the scheme would be required to waive their right to go to court on the same case.

It is clear that the Department of Health’s proposals constitute potentially significant reforms to the way clinical injuries are compensated by the NHS (and, given the sums

\footnotetext{
${ }^{2}$ As an indication of the responses such figures have engendered, the Public Accounts Committee says they "represent a clear failure of the NHS and the legal system to deal with patients with speed and compassion", and describes the costs as "a drain on scarce resources for improving patient care.” (p. 6).
} 
involved, to resource allocation within the NHS). Yet the empirical basis for the debate to which they contribute has not been strong in the UK. ${ }^{3}$ The purpose of this paper is to present findings from new research aimed at casting fresh light on this debate. The research was commissioned to inform the deliberations of the Secretary of State for Health's Advisory Group (see Fenn et al, 2002). The paper is structured as follows. Section 2 reviews briefly the economic theory underlying the objectives of patient compensation schemes. In Section 3 we describe the institutional arrangements within which the English clinical negligence scheme operates, ${ }^{4}$ discuss its annual cash cost and assess its deterrence effects. Section 4 summarises what is known about the structure and performance of several overseas no-fault schemes in order to draw lessons for reform in England and identify data requirements for modelling such reform. In Section 5 we estimate, for the first time, the cost of possible reforms, paying particular attention to "small claims" fault-based schemes of the type proposed in DoH (2003), and to a commonly cited model for no-fault compensation in England: the Swedish no-fault scheme. Section 6 concludes the paper.

As stated in the Introduction, patient compensation schemes are a means by which two objectives can be pursued: the cost of the harm can be transferred from the patient (the 'compensation' objective); and the clinician can be given an incentive to take appropriate care to avoid making mistakes which may harm other patients (the 'deterrence' objective). All patient compensation schemes attempt to deliver these objectives jointly with varying degrees of success, and with varying administration costs. $^{5}$

\footnotetext{
For example, see Fenn et al (1994; 2000), Vincent (2001).

${ }^{4}$ Our data and discussion relate to England unless otherwise stated. However, as Scotland and Wales currently have clinical negligence schemes similar to that in England (i.e. fault-based) but with minor differences, many of the issues we discuss are also relevant to them.

${ }^{5}$ In some systems, the two objectives have been explicitly separated (or “decoupled”); one mechanism can be set up to deliver compensation to patients, another to secure medical accountability.
} 


\subsection{Compensation}

The economic basis for viewing compensation schemes purely as solutions to a risksharing problem between patients and clinicians is weak. ${ }^{6}$ There are likely to be many more efficient mechanisms for delivering risk transfer benefits to patients facing possible losses through medical care, including private first party insurance (e.g. an income replacement or medical expenses policy), a negotiated sick pay scheme through which employers meet losses as part of a wages and conditions package, or social insurance (e.g. disability benefits). Indeed Danzon (2000a) raises the question of why someone should be compensated for illness when caused by medical care but not if similar losses arise as the result of (say) genetically inherited birth defects. Following this line of argument, it is possible that the most equitable and administratively efficient means of delivering the compensation objective would in fact be via a social insurance programme, and - as will be seen below - the interaction between clinical negligence schemes and insurance provision is an important and sometimes overlooked influence on the performance of such schemes.

\subsection{Deterrence}

Harmful outcomes arising from medical treatment can be reduced if those involved take care to avoid them. However, to the extent that care is costly, doctors may need to be given incentives to provide it. One natural incentive against insufficient care levels is to make the person causing the harm (assuming causation can be determined) liable for the costs involved, if he fails to supply care beyond a sufficient threshold (i.e. behaves 'negligently'). In theory, the appropriate level of care $(x)$ minimises total accident costs $x+D(x)$, where $D(x)$ is the resulting damages, assumed to be decreasing and convex in $x$. The optimal level of care solves $1+D^{\prime}\left(x^{*}\right)=0$ : the marginal social benefit from an extra unit of care should equal its marginal social cost. $^{7}$

When the standard of care is known to everyone, and observable (to individuals and courts), it is straightforward to show that negligence liability would produce socially

\footnotetext{
${ }^{6}$ It should be noted, however, that some lawyers see the payment of compensation by those responsible as an end in itself ("corrective justice”).

${ }^{7}$ See Miceli (1997) for more detailed models of liability rules.
} 
optimal levels of care (i.e. deterrence). Letting $u(W)$ be the clinician's utility of wealth, his care level solves: “ $u(W-x)$ if $x \geq x^{*} ; u(W-x-D(x))$ if $x<x^{*}$ ”. Provided $D$ $>x^{*}$, the clinician will choose the efficient level of care. ${ }^{8}$ Figure 1 explains this result. The total costs of the accident are given by the curve $x+D(x)$ and are minimised at $x^{*}$, the optimal care level. The negligence rule results in the clinician facing no further liability above $x^{*}$, creating a discontinuity in his cost function, which becomes $P Q R S$. Clearly, his cost minimising decision is to set $x=x^{*}$.

Figure 1: Optimal care under negligence and strict liability

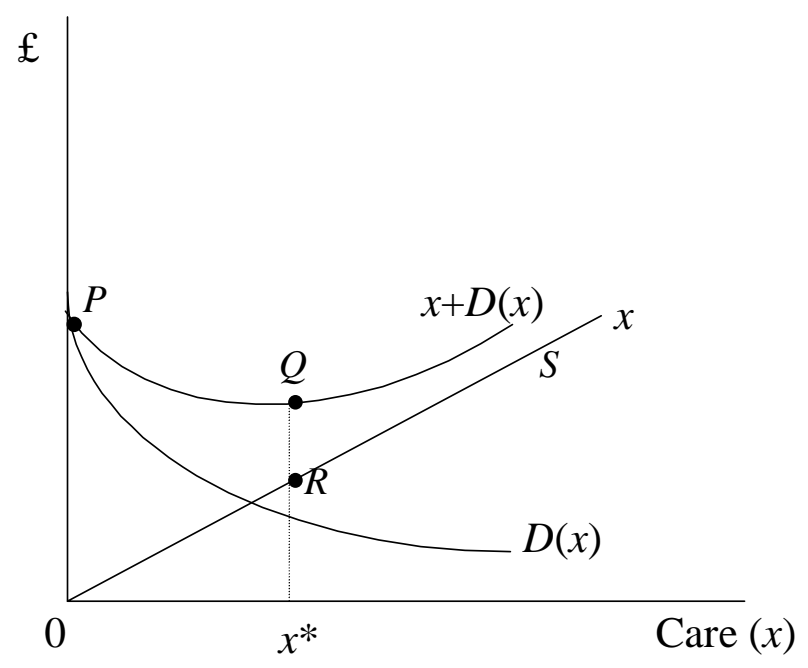

Of course, common sense and the observed real-world demand for liability insurance tell us that these conditions are strict and that overwhelming information problems will typically prevent such a result. For example, courts cannot determine precisely what care a clinician has taken, while it is often the case that opinions differ as to what constitutes an appropriate standard of care. Further, clinicians may be unsure of the level of damages involved in the case. These can have numerous implications for the successful operation of a negligence system. Particularly important here is that parties worried about mistakenly being found liable or facing uncertain damages may over-invest in care or reduce their involvement in that clinical area. In the medical

\footnotetext{
${ }^{8}$ The condition $D>x^{*}$ becomes more likely to hold if $D$ is more widely interpreted to include any reputational loss suffered by a negligent clinician. Interestingly, Lewis et al (2003) suggest that UK personal injury litigation typically underestimates any loss-of-earnings component of $D$.
} 
context, such behaviour is known as 'defensive medicine'. 9 Thus, when assessing a negligence rule for medical cases we should, ideally, compare the deterrence benefits of such a rule with the defensive costs it may induce.

One way to overcome this problem may be to move to a system of 'strict liability', where proof of causation alone is sufficient to trigger compensation from the party whose actions led to the harm. Cummins et al (2001) identify strict liability schemes with no-fault set-ups: in both cases payment of compensation is not contingent on the attribution of fault. Because payment is made regardless of the injurer's level of care, it overcomes problems associated with unpredictable care thresholds. Also, to the extent that the injurer faces the costs of his actions, it can be shown to provide optimal incentives for care. ${ }^{10}$ Figure 1 illustrates this result since, under strict liability, the clinician's total cost function mirrors the court's (i.e. $x+D(x)$ ), so that he sets $x=x^{*}$. However, once again real-world imperfections make this unlikely in practice; in particular, it is unclear whether courts can observe damage levels and set suitable penalties accordingly. Again, the prospect of excessive damages can stimulate excessive (i.e. defensive) levels of care, underlining the importance of recognising the trade-off between deterrence benefits and defensive costs when evaluating such schemes. ${ }^{11}$

Another important consideration when evaluating the deterrence effects of both liability rules outlined above is the role of third-party payers such as liability insurers. To the extent that potential injurers shift risk onto insurers they may avoid facing costs sufficient to induce appropriate care. However, a range of measures available to insurers can mitigate these concerns, including experience-rated premiums and copayments/deductibles. ${ }^{12}$ An alternative third-party payer may be the individual's employer (e.g. a clinician’s hospital). ${ }^{13}$ Under such ‘enterprise liability schemes' (a version of which has existed in the NHS since 1990; see below and also Weiler,

\footnotetext{
${ }^{9}$ Danzon (2000b) notes another (of many) problems in the case of clinical negligence. If the care threshold is set by practitioners' reports of 'best practice' (as is typically the case), this may lead to sub-optimal negligence rules to the extent that systematic errors exist within this 'best practice'.

${ }^{10}$ Now the clinician maximises $u(W-x-D(x))$, yielding $x=x^{*}$.

${ }^{11}$ Cummins et al (2001) show that it is not clear a priori whether negligence or strict liability generates higher care levels. For negligence to produce this, a sufficient condition is that courts are 'sufficiently accurate' in assigning fault.

${ }^{12}$ The insurer may also seek to monitor its policyholders' behaviour but the transactions costs of doing this may be prohibitive or damaging to the efficiency of the underlying liability rule.

${ }^{13}$ In the case of US health plans, the hospital and insurer often jointly bear the risk.
} 
1991), the hospital may in turn seek to shift risk onto an insurer, and issues similar to those above will then arise. Of course, in order to ensure that employees have incentives to supply care, the enterprise will need to have mechanisms in place to monitor, record, investigate and, possibly, punish any acts for which it is held liable.

\subsection{Administrative efficiency}

Whether patient compensation schemes actually compensate, deter, or do both, there is a second order question about the administrative efficiency with which they pursue these objectives. Much of the debate about the need for reform in England (and elsewhere) has in fact stemmed from a perception that fault-based schemes are characterised by unnecessary cost and delay. As a consequence, it is argued, those in need of compensation have been unable to obtain it, and those responsible have not always been held to account. A scheme designed purely to compensate should be able to do so with no greater administrative overheads than private and social insurance schemes. However, the cost of operating a system designed to achieve general deterrence benefits should also be judged in relation to the benefits from injuries averted. It is possible to make a case for the costly and lengthy process of investigation required by the courts as a means for identifying and remedying poor quality care. Of course, the extent of investigation costs will depend on the burden of proof. Danzon (2000b) observes that negligence-based liability for clinical negligence appears to involve higher administrative costs than alternative means of providing compensation (see Section 4 below).

\section{CLINICAL NEGLIGENCE IN ENGLAND}

\subsection{Institutional background}

Clinical negligence in England has changed substantially over the last decade or so, and its evolution well illustrates many of the theoretical issues outlined above. Prior to 1990, clinicians were individually liable for the consequences of their negligence, and therefore patients frequently cited both the hospital and the clinician when bringing a claim. The hospital, as part of the NHS, would meet the cost out of its budget, while the clinician would meet the cost from one of several medical practitioner's risk pools 
to which he subscribed. After 1990, the NHS assumed responsibility for clinicians' negligence in the course of NHS work, so that patients now claim against the hospital in question, citing the clinician as the individual at fault if necessary. One rationale for this change (effectively a system of enterprise fault liability) was that hospitals are better placed than individual clinicians to institute risk management policies, although, for such policies to be successful, the hospital must resolve the principalagent problem that may arise between itself and its employees. NHS hospital Trusts now have a certain amount of financial autonomy, and can in principle pass on some of the risk from medical accidents to Primary Care Trusts (PCTs) who refer patients and commission much of the treatment that hospitals provide. Moreover, since 1995, hospital trusts have been able to pool their clinical negligence risks through an arrangement known as the Clinical Negligence Scheme for Trusts (CNST). This scheme meets claims arising from incidents since April 1995 in return for contributions to the risk pool, and is administered by the NHS Litigation Authority (NHSLA). ${ }^{14}$

Initially, as with other pooling arrangements, Trusts could influence their contributions by choosing an excess, below which they met all the costs of a claim, ${ }^{15}$ and in $200145 \%$ of Trusts chose an excess of $£ 10,000,35 \%$ chose $£ 25,000,13 \%$ chose $£ 50,000$ and the remaining $7 \%$ chose an excess of $£ 100,000$. However, from April 2002 the NHSLA assumed financial responsibility for 100\% of all claims against NHS hospitals (i.e. the excess level has been set at zero for all member trusts). This change was justified on the grounds that the decentralisation of accounting responsibilities for small value claims placed a burden on hospital management, and led to difficulties in producing consolidated estimates for the NHS accounts. It was also argued that, by assuming responsibility for all claims, the NHSLA would be in a better position to report on national trends in the frequency and cost of medical litigation, and to identify those activities and procedures most at risk of litigation. ${ }^{16}$

\footnotetext{
${ }^{14}$ A further scheme, the Existing Liabilities Scheme (ELS), covers claim costs from incidents prior to April 1995. In effect, this is a "run-off" scheme, under which the liabilities incurred by health authorities prior to the formation of trusts are settled.

${ }^{15}$ Trusts also paid 20\% of the claim above the excess up to a pre-specified upper limit.

${ }^{16}$ In principle, data on claims could also be coordinated with data on reported adverse events, recording of which is now the responsibility of another agency, the National Patient Safety Agency.
} 
Set against the potential benefits of transferring responsibility for claims from hospitals to the NHSLA are some potential costs. In particular, as discussed above, it is usually recognised that those who cause injuries should themselves face at least some of the injury costs, in order to provide potential injurers with an incentive to take care. In the health care sector, this issue is complicated by the fact that patients may be injured due to the interaction of multiple factors leading to organisational, rather than individual, failures. In those circumstances, it becomes important to provide hospital managers with incentives to take responsibility for identifying system failures and implementing risk management procedures. Arguably, the combined effect of switching financial responsibility for negligence from individual clinicians to hospitals, and imposing a minimum excess level as a condition of pooling risks through the CNST, represented a coherent policy in this respect in the UK during the 1990s. However, the financial discipline and incentives this policy created have now been removed by reducing excess levels to zero.

The one remaining financial incentive to pursue good risk management practices in the NHS's current liability arrangements is through CNST subscription discounts, which are awarded to hospitals who achieve certain risk management standards as assessed by the NHSLA. In 2001, 29\% of Trusts had no discount, $62 \%$ had a $10 \%$ discount, $8 \%$ had a $20 \%$ discount, and fewer than $1 \%$ had a $25 \%$ discount. While these discounts are related to risk management standards that are designed to include the presence of, inter alia, adequate incident reporting and complaints management systems, they are a reflection of processes, not outcomes. ${ }^{17}$

Prior to April 2001, hospitals with low excess levels faced a lower expected cost from increased litigation than those with high excess levels. Consequently it was possible for us to test whether any relationship could be detected between a hospital's litigation rate, measured by the observed claim frequency, and the hospital's previously chosen excess levels and assessed risk management discounts (Fenn et al, 2003). Our results (obtained using count data methods) indicate that high excess levels reduced the observed frequency of new claims and the observed stock of outstanding claims in 2001. This evidence lends support to the view that hospitals with a higher share of

\footnotetext{
${ }^{17}$ A second discount which does potentially give hospitals a financial stake in reducing the number and cost of claims is given by the NHSLA in relation to hospitals' claims experience. However, it is unclear how claims experience is measured for this purpose.
} 
liability are more likely to take action to reduce the frequency and stock of claims - a 'deterrence effect'. Consequently, the recent reduction of CNST excess levels to zero may have adverse consequences in terms of a higher number of claims. The evidence relating to risk management discounts is weaker, but there is a tentative suggestion that the stock of outstanding claims was lower for hospitals with high discounts for their risk management activities. ${ }^{18}$

\subsection{The financial cost to the NHS}

Over the last decade there have been well-documented difficulties in reliably estimating the full NHS cost of clinical negligence (Towse and Danzon, 1998; Fenn et al, 2000). First, there has been a lack of appreciation of the distinction between annual costs and outstanding clinical negligence liabilities - the latter being the provision in accounts for the stock of claims against the NHS that have yet to be settled. Second, there has been a progressive transfer of liabilities from the now disbanded Health Authorities to the NHS Trusts (each of which has separate accounting procedures), and in turn from Trusts to the NHSLA, as described above. Untangling the total cost to the NHS of clinical negligence has consequently been problematic. The transfer of liabilities to the NHSLA is now complete, however, and it is possible to obtain data on overall cash paid out in damages and legal costs from the combined risk pools. From data provided to us by the NHSLA, we have estimated that the total in awards paid out to patients in 2000/01 was $£ 249 m$, the total of legal costs incurred by claimants was $£ 49 \mathrm{~m}$, and the total of legal costs incurred by defendants was $£ 29 \mathrm{~m}$, making the overall financial cost of clinical negligence $£ 327 \mathrm{~m}$ for that year. ${ }^{19}$ This compares with a total cost to the NHS generally agreed to be in the region of $£ 50 \mathrm{~m}$ in 1990 (Fenn et al, 1994).

This increase in the cost of clinical negligence is partly the result of increased litigation, and partly the result of higher damage awards and legal costs. Fenn et al

\footnotetext{
${ }^{18}$ While it might be argued that both excess levels and risk management activities are endogenous, the excess levels and discounts used in our analyses were set at the beginning of the year, and can therefore be assumed to be predetermined.

${ }^{19}$ Our own estimates for these costs in 2000/01, based partly on a survey of NHS Trusts, were slightly lower at $£ 294 \mathrm{~m}$, due to a difference in the definition of claim closure. We project this cost rising to approximately $£ 405 \mathrm{~m}$ by 2005/6, reflecting increases in the litigation rate which have occurred over the last ten years or more, but assuming a steady state in terms of future claim frequency and severity (Fenn et al, 2002).
} 
(2000) used the only comprehensive historic data source in England - from the Oxfordshire Health Authority - to estimate an average annual increase of $11 \%$ in the number of claims settled each year over the period 1990-1998, or 7\% per annum after adjustment for the increase in hospital activity. During this period the rate of litigation increased from 0.46 to 0.81 settled claims per 1,000 finished consultant episodes, about $40 \%$ of which successfully obtained compensation. For England and Wales as a whole, using NHSLA data we estimate that there were approximately 3,500 claims settled with payment in 2000/01, at an average award of around £73,000. The median award is much lower, at $£ 11,000$, illustrating the skewness of the damage distribution with a small number of high cost settlements each year, particularly related to brain injuries at birth. A large number of claims are settled for relatively low damages, and yet the combined legal costs can still be substantial: for claims settled under $£ 10,000$ (almost half of all claims settled), we estimate that the combined legal costs were approximately $£ 7,000$ on average.

Finally, because both the rate of litigation and the mean award are increasing, the ultimate financial cost of claims against hospitals which are currently outstanding is difficult to estimate. As noted in the Introduction, in 2000/01 total NHS provisions for future settlements of negligence claims stood at $£ 4$.4bn. However, the mean duration of claim from initiation to closure is over five years, and some claims take decades to settle. The strength of evidence for these cases is not always clear, and rough estimates have to be made about the likelihood of payment on each claim, or the proportion of claims which will get paid in aggregate, in order to project forward the cost of future settlements. For both these reasons, the global figure of $£ 4$.4bn for NHS provisions is not particularly helpful as a guide for policy without further information about the process by which clinical negligence claims are settled and will be settled in future.

\section{INTERNATIONAL COMPARISONS OF CLINICAL NEGLIGENCE AND NO-FAULT SCHEMES}

Few international comparisons have been made of the characteristics or performance of different schemes for compensating clinical injuries, partly because of the difficulties of assembling reliable data. Yet such comparisons are instructive, 
particularly when reforms are under consideration in England. Table 1 provides data to help illustrate several lessons from other jurisdictions, including no-fault clinical compensation schemes as well as two (relatively small) US jurisdictions for which comparable data are available: Utah and Colorado. The latter are of particular interest because in 1992 both states instituted programmes of research into their handling of clinical negligence claims, and piloted no-fault schemes from $1995 .^{20}$ This was a response to concerns about the level of tort litigation and the associated premium levels charged to clinicians.

\subsection{Eligibility criteria}

It is clear from Table 1 that, consistent with their rejection of negligence criteria, the no-fault schemes compensate a larger number of claimants than does tort in England. (The Florida no-fault scheme is confined to birth injuries, which explains the relatively low claims rate and very high average payment). Even so, an appreciable minority of claims is rejected under each scheme. To the extent that no-fault schemes permit the compensation of large numbers of claimants, they face a high potential cost. For example, the New Zealand Accident Compensation Scheme's nominal costs grew by 20\% per annum between 1975 and 1989 (NZBR, 1998). ${ }^{21}$ Accordingly, designers of such schemes face a trade-off between cost and coverage. Typically, this trade-off is dealt with in two ways.

\footnotetext{
${ }^{20}$ Fuller institutional detail can be found in Fenn et al (2002).

${ }^{21}$ These costs relate to the whole range of accidents covered by the no-fault scheme in New Zealand (e.g. road and workplace); medical injuries were not separately accounted for. However, the figures still make our point - that no-fault schemes can be open to substantial cost.
} 
Table 1: Comparative data on no-fault compensation schemes in Sweden, New

Zealand and the United States, and tort in England

\begin{tabular}{|c|c|c|c|c|c|c|}
\hline & \multicolumn{5}{|c|}{ No-fault schemes } & \multirow{2}{*}{$\begin{array}{c}\text { Tort } \\
\text { England }\end{array}$} \\
\hline & Sweden & NZ & $\begin{array}{l}\text { Florida (birth } \\
\text { injuries only) }\end{array}$ & $\begin{array}{c}\text { Utah } \\
\text { [\& Utah with } \\
\text { severity } \\
\text { threshold] }\end{array}$ & $\begin{array}{c}\text { Colorado } \\
\text { [\& Colorado } \\
\text { with severity } \\
\text { threshold] }\end{array}$ & \\
\hline Population (million) & 8.910 & 3.737 & $0.256^{\mathrm{a}}$ & 2.233 & 4.301 & 50.225 \\
\hline $\begin{array}{l}\text { Annual number of } \\
\text { claims closed }\end{array}$ & 7,775 & 1,743 & 70 & $\begin{array}{c}2,940^{\mathrm{b}} \\
{\left[1,465^{\mathrm{b}}\right]}\end{array}$ & $\begin{array}{l}5,919^{b} \\
{\left[973^{b}\right]}\end{array}$ & 8,660 \\
\hline $\begin{array}{l}\text { Annual number of } \\
\text { claims closed per } \\
\text { 100,000 popn. }\end{array}$ & 87 & 47 & 27 & $\begin{array}{l}132 \\
{[66]}\end{array}$ & $\begin{array}{l}138 \\
{[23]}\end{array}$ & 17 \\
\hline $\begin{array}{l}\text { Percent of closed claims } \\
\text { involving payment to } \\
\text { claimant }\end{array}$ & $47 \%$ & $60 \%$ & $47 \%$ & n.a. & n.a. & $40 \%$ \\
\hline $\begin{array}{l}\text { Annual number of paid } \\
\text { claims per } 100,000 \\
\text { popn. }\end{array}$ & 41 & 28 & 13 & n.a. & n.a. & 7 \\
\hline $\begin{array}{l}\text { Average payment } \\
\text { (£2001) }\end{array}$ & $£ 7,078$ & $£ 3,610$ & $£ 404,588$ & $\begin{array}{c}£ 25,722 \\
{[£ 29,836]}\end{array}$ & $\begin{array}{c}£ 18,115 \\
{[£ 44,616]}\end{array}$ & $£ 72,953$ \\
\hline $\begin{array}{l}\text { Administration cost } \\
\text { per case ( } £ 2001)\end{array}$ & n.a. ${ }^{\mathrm{c}}$ & n.a. $^{\mathrm{c}}$ & $£ 46,213$ & $\begin{array}{c}£ 7,717 \\
{[£ 8,951]}\end{array}$ & $\begin{array}{c}£ 5,435 \\
{[£ 13,385]}\end{array}$ & $£ 18,744$ \\
\hline
\end{tabular}

Sources: See Fenn et al (2002)

Notes:

${ }^{a}$ The appropriate population for the Florida Neurological Injury Compensation Act scheme (NICA) is annual births, which we obtained from the US Census Bureau for 2000-2001.

b The recent nature of the Utah and Colorado pilot schemes mean that we report the estimated number of compensable events, based on analysis of records; actual claims will be a subset of compensable events (see Studdert et al (1997), p. 32). Lack of claims data also explains the empty paid claim cells for Utah and Colorado.

c We do not have comparable data on administrative costs for Sweden and New Zealand. However, Danzon (2000b) notes that both are low. Thus, in Sweden, the administration cost is "14-18\% of total premiums [that fund the scheme], compared to roughly 60\% in the US" (p. 1390), while the New Zealand no-fault accident scheme (that includes clinical injuries) has overhead costs "less than $10 \%$ of total expenditures" (p. 1393).

\subsubsection{Severity}

Costs can be controlled by tightly defining the severity of injury that qualifies for compensation. All schemes do this, and Utah and Colorado provide interesting 
illustrations. In Table 1, we present the baseline figures for the performance of these schemes, but also a set of figures based on Studdert et al's (1997) application of severity thresholds. Thus, in Utah, application of a minimum 4-week-off-work injury threshold and a maximum damage level for pain and suffering reduces claims from 132 per 100,000 population to 66. Even larger reductions are achieved in Colorado by an 8-week threshold and the exclusion of compensation for foregone household production. Thus, expenditure control is achieved at the expense of smaller value claims (which tend to form the bulk of claims, as the fall in claim rate in Table 1 illustrates).

\subsubsection{Error-based injuries}

Both the Swedish and New Zealand schemes faced significant cost increases in the '70s and '80s. As a result, the definition of a compensable injury was altered to tighten eligibility. Effectively, as Danzon (2000a, b) notes, in both cases an element of fault was re-introduced. Taking Sweden as an example, a claim is compensable if (1) it occurred with "substantial probability" as a direct consequence of clinical error and (2) either the treatment was not clinically justified or the injury could have been avoided by treating it differently. To the extent that Utah and Colorado have also invoked "Swedish schemes", it appears hard to define a basis for compensation that does not recognise clinical error.

\subsection{Collateral offset}

Awards in England under tort are on average higher than awards under the no-fault schemes (apart from those restricted to birth-related injuries, such as Florida). An important reason for this is that most no-fault schemes take the role of second payers of compensation. The generous social security and public health care systems in Sweden are the primary sources of compensation in that country, while in the US the costs to the no-fault scheme of paid claims may be recovered or offset from collateral sources such as private health insurers. By comparison with no-fault benefits, tort awards are high as a consequence of the legal principle by which the injurer bears all of the costs incurred by his actions. Under an English no-fault scheme, collateral offset would presumably mean the NHS and social security system jointly taking responsibility for being first payers for health care costs and basic income 
replacement respectively, with the patient compensation scheme meeting the cost of out-of-pocket expenses and non-recovered loss of earnings. ${ }^{22}$

\subsection{Parallel tort}

An important decision when designing a no-fault scheme (or a composite scheme) is the extent to which claimants also have recourse to the tort system. ${ }^{23}$ For example, in Florida 'leakage rates' of almost 20\% into tort have been reported by Sloan et al (1997). Interestingly, Swedish claimants also have recourse to tort but are far less frequent litigators. One important reason is that the generous social security provision mentioned above significantly reduces tort awards, making litigation 'uncompetitive'. A further implication of both collateral offset and parallel tort is that the overall cost of patient compensation is unlikely to be isolated within the no-fault arrangements themselves.

\subsection{Administration costs}

One of the justifications for a no-fault scheme is the saving in administrative costs that follows from not having to prove liability in a complex legal case. The figures for Utah and Colorado in Table 1 tend to confirm this. Studdert et al (1997) suggest administrative costs of 30\% per claim dollar under no-fault (compared to 55\% under tort in these States). Estimates for Florida in Bovbjerg et al (1997) suggest that nofault administrative costs resemble fixed costs so that the cost/damages ratio falls as case value rises.

\subsection{Decoupling of compensation and deterrence}

We have noted that no-fault schemes may suffer from a diminution of deterrence incentives, unless the clinician continues to face the prospects of paying the no-fault award (which usually is not the case). Instead, such schemes have sought to

\footnotetext{
${ }^{22}$ It is interesting to note that DoH (2003) appears to reflect this thinking by anticipating that the NHS will, where possible, provide packages of care under its small claims and birth-related neurological injury schemes. This will have the effect of reducing the financial sum required for full compensation under the schemes.

${ }^{23}$ To the extent that the European Convention on Human Rights requires citizens to have access to independent tribunals and appeals procedures, reform may be unable to foreclose this option.
} 
“decouple” the compensation and deterrence objectives and to pursue deterrence by some form of monitoring and reporting system, the costs of which do not appear in Table 1. For example, in Sweden a Medical Responsibility Board performs this role but tends not to be notified when a claim is brought against a clinician (Danzon, 2000b). Bovbjerg et al (1997) raise a similar concern about parallel arrangements in Florida. In New Zealand, by contrast, it was intended to levy experience-rated premiums on clinicians, but according to Paterson (2001) this has never happened. ${ }^{24}$ Studdert and Brennan (2001) are more sanguine about the prospects for experiencerating and enterprise liability in Utah and Colorado. Thus, while the deterrence effects of any scheme (fault or no-fault) are hard to measure, there is some evidence that the costs of making alternative deterrence arrangements alongside no-fault schemes may be overlooked.

\subsection{Data requirements for modelling tort reform}

Apart from highlighting some key issues in clinical negligence reform, the discussion above also provides important information on the kinds of data necessary to model the effects of any proposed change. In particular, we need to know the size of the likely pool of claimants, injury severity (for sensitivity analysis of alternative thresholds), leakage rates across the reformed scheme and tort, the administrative costs of tort and the proposed alternative and institutional details like the extent of any proposed collateral offset. While our research has helped uncover reasonable data on the existing tort scheme in England, very few of these data are available for modelling an alternative scheme. Accordingly, we begin the next section with a discussion of the data collection we have undertaken and the informed assumptions we have made to model reform proposals in England.

\section{COST ESTIMATES FOR ALTERNATIVE SCHEMES}

We now provide estimates for the impact of alternative patient compensation schemes if they were introduced in England. Whilst such an exercise inevitably involves some degree of uncertainty, our estimates draw on a combination of information sources

\footnotetext{
${ }^{24}$ Paterson laments a "medical profession that is shielded from damage claims for negligence.” (p. 14) and also suggests that no-fault has not increased the incidence of "whistle-blowing" in New Zealand. This experience contradicts the arguments made by Kennedy (2001): see the Introduction.
} 
that has hitherto not been available. Despite the uncertainty surrounding our estimates, it is hard to imagine a rational debate on clinical negligence reform taking place without some explicit attempt at estimating the potential claims volumes and costs that a change of regime might generate.

We choose to simulate two alternative reform proposals that have achieved some prominence in recent debate:

i. A 'Swedish-style' scheme modelled on the no-fault arrangements available in that country. This model underlies the no-fault experiments in Utah and Colorado and has been seen as a natural template for reform in England.

ii. A 'small claims' scheme, as proposed in DoH (2003), whereby cases valued below a given threshold are offered speedy access to compensation based on the administrative assessment of fault, while larger ones pursue the traditional tort route. ${ }^{25}$

To model these schemes, we draw partly on available data from the international experience described in the previous section, and partly on a population survey specially commissioned for our research and undertaken in 2001 by MORI.

\subsection{Population survey}

To the extent that alternative schemes remove the need to establish fault, or reduce the cost of claiming, it may be objected that they would increase the volume of claims, perhaps offsetting any administrative savings. We have seen above that this is the overseas experience. In order to consider this for England, it is necessary to estimate the number of potential claimants for injuries caused as a result of medical care received, and also to estimate the proportion of these who might demand compensation if eligibility criteria or access costs were to change. We therefore designed a questionnaire to provide data on the incidence of adverse events in the English population and, when they occurred, to assess where they happened, their severity in terms of health and employment, the response considered most

\footnotetext{
${ }^{25}$ The small number of (typically high cost) cases that would fall under the Department of Health's proposed scheme for birth-related neurological injuries means that we do not assess the cost effects of this in detail.
} 
appropriate, whether a legal claim was pursued, and the amount of compensation respondents considered acceptable. In addition, demographic information was obtained on respondents' age, sex, region, level of qualification/education, social class, and household income. The questionnaire was administered in face-to-face interviews to a randomly selected sample of adults in four waves at weekly intervals during October/November, 2001. Approximately 2,000 individuals were interviewed in each wave, giving a total sample size of 8,206.

In response to an initial filter question, $4.8 \%$ of the sample believed that over the last three years they had suffered some illness, injury or impairment that in their opinion was caused by their medical treatment or care. This annual rate of $1.6 \%$ is broadly consistent with Vincent et al's (2001) estimate that 10\% of hospital episodes involve some form of adverse event, and it provides an upper bound for the potential number of claims. Approximately 55\% of those reporting some event claimed that it was insignificant, emotional only or minor and temporary, 15\% reported a temporary major disability and almost 30\% claimed that the event had had a permanent impact on their health. A similar pattern of response was found with respect to impact on employment: of the $70 \%$ of respondents who were in work at the time of the event, approximately $48 \%$ stated that the impact was not relevant, non-existent or minor, $16 \%$ reported having to take at least one month off work as a result of the event, and $35 \%$ stated that they had had to take at least one year off work, retire, or move to a less demanding job.

Respondents who considered that they had experienced an adverse event were then asked what remedy they considered to be most appropriate. The remedy most commonly considered appropriate was an apology or explanation (34\%), followed by an inquiry into the causes (23\%) or support in coping with the consequences (16\%). $11 \%$ of respondents indicated that financial compensation would have been the most appropriate response. In line with this finding, $11.4 \%$ of respondents stated that they had in fact pursued a legal claim for financial compensation. The main reasons given for not pursuing a claim were that the respondent did not want financial compensation (36.7\%) or that it had not occurred to them (19.5\%). Some 6.8\% were worried about time-consuming complexity and $2.3 \%$ were worried about cost: we interpret this as suggesting that the proportion of potential claimants seeking financial compensation 
could increase by $80 \%((2.3+6.8) / 11.4)$ if the costliness and complexity of the process was significantly reduced. Those with more severe claims were more likely to have considered financial compensation.

Finally, the survey provided some evidence on the relationship between pursuit of a financial claim and household income levels. As Figure 2 shows, the distribution of financial claims by income distribution was clearly bimodal, with higher proportions seeking financial compensation at lower and higher incomes. This evidence is consistent with the interpretation that, whereas patients in lower income bands are able to pursue compensation through legal aid, and those in upper income bands have the means to access costly legal services, middle income households are less able to obtain access. It also suggests a plausible limit to the propensity to make a legal claim in England: in the absence of significant cost pressures, some $18-20 \%$ of those with injuries are prepared to pursue financial compensation.

Figure 2: Proportion of respondents pursuing a legal claim for financial compensation

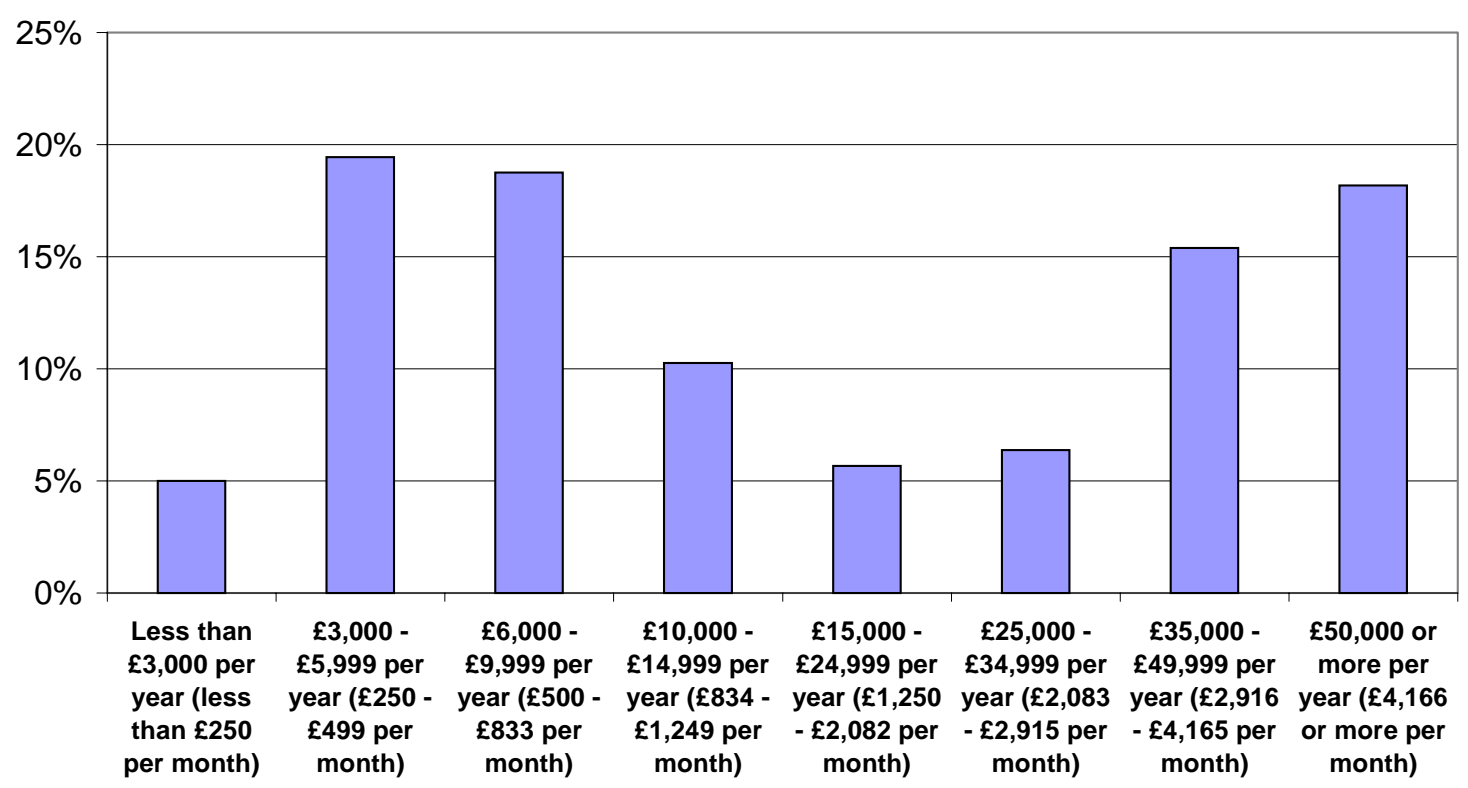

Compensation, by household income

\subsection{Assumptions}

Table 2 reports the assumptions made, baseline values and sources for the variables necessary to estimate the number and cost of claims likely to be made in England 
against NHS hospitals under a Swedish style no-fault compensation scheme. These are derived from the responses to questions contained in our population survey described above, and relate to the annual rates of perceived preventable adverse events, and the proportions of these that occur in NHS hospitals.

As the claimants would no longer need to establish fault, the administrative cost of settling claims is based on Department of Health estimates for administering small claims through various 'fast-track' procedures, ranging from $£ 300$ to $£ 4,100$; a figure of $£ 2,000$ was suggested by the Department as a base case estimate, around which sensitivity analysis could be undertaken. Concerning the mean award, the generosity of a Swedish style no-fault scheme in England would depend on whether various damage caps or limitations are adopted and on the interface with the social security system $^{26}$; it is difficult to estimate the extent of the savings over tort damages, but a figure of $75 \%$ of the mean award under the current tort scheme was chosen as a starting value; again, sensitivity analysis was undertaken around this figure.

Table 3 sets out our estimates concerning the number and cost of claims under an alternative 'small claims' scheme with various ceilings, and the sources of our information. The central threshold value we consider (a ceiling of $£ 30,000$ ) corresponds to the proposal put forward for discussion by the Department of Health (DoH, 2003). Such a scheme would retain the need to establish fault, but this would be undertaken by means of a streamlined 'fast-track' assessment procedure along similar lines to that assumed for a no-fault scheme and at a similar administrative cost. We estimate that a low cost, fast access to justice scheme could increase the number of patients who claim by $80 \%$ over the current system, a figure derived from responses to our population survey described above. The quid pro quo for this improvement in access is assumed to be a somewhat less generous award: the Department of Health has suggested ${ }^{27}$ a reduction of $15 \%$ compared with the compensation that would be obtained under tort. As a consequence of this, we assume that $20 \%$ of those eligible for the 'fast-track' scheme would opt instead for the traditional tort route, based on data on the leakage rate from the Florida no-fault

\footnotetext{
${ }^{26}$ As pointed out in the previous section, one of the reasons for the affordability of no-fault in Sweden is its integration with a generous social security system on benefits. We are unable to assume this for England.

${ }^{27}$ Private correspondence.
} 
scheme into tort. This proportion is likely to vary depending on the injury severity and other features of the new scheme. Our estimate for the mean award under the scheme is therefore based on the mean tort award under each threshold value (obtained using NHSLA data), adjusted for the assumed savings and the proportion opting out. For those patients who are not eligible for the scheme because their claim is valued over the threshold, we assume that they continue to receive the mean tort award observed for claims over that value, and incur the mean legal costs observed for those claims. Finally, we also make assumptions about the likelihood and cost of legal advice and appeals by claimants under the scheme, provided to us by the Department of Health.

Table 2: Assumptions determining number of claims made under Swedish-style no-fault compensation scheme

\begin{tabular}{|c|c|c|}
\hline Variable & Baseline & Source \\
\hline Population of England, 2001 & $50.225 \mathrm{~m}$ & ONS \\
\hline $\begin{array}{l}\text { Annual rate of perceived preventable } \\
\text { adverse events }\end{array}$ & 0.016 & MORI survey \\
\hline $\begin{array}{l}\text { Proportion of events occurring in NHS } \\
\text { hospitals }\end{array}$ & 0.547 & MORI survey \\
\hline $\begin{array}{l}\text { Proportion of preventable adverse events } \\
\text { giving rise to a claim }\end{array}$ & 0.19 & MORI survey \\
\hline Swedish proportion of unpaid claims & 0.58 & Studdert et al (1997) \\
\hline Administrative cost of settling claims (£k) & 2 & Department of Health \\
\hline Mean award per case (£k) & 54.71 & $\begin{array}{l}\text { 75\% of observed mean award for } \\
\text { Existing Liabilities Scheme (ELS) } \\
\text { and Clinical Negligence Scheme } \\
\text { for Trusts (CNST) combined }\end{array}$ \\
\hline
\end{tabular}

\subsection{Simulations}

Using the assumptions in Table 2 above, Table 4 reports the estimated total annual cost of implementing a Swedish-style no-fault compensation scheme for hospital claims in England, with eligibility determined by demonstrating some form of preventability associated with the adverse event caused by medical care. 
Table 3: Assumptions determining number and cost of claims made under 'small claims' scheme

\begin{tabular}{|c|c|c|c|c|}
\hline & \multicolumn{3}{|c|}{ Ceiling value of scheme } & \multirow[b]{2}{*}{ Notes } \\
\hline & E10k & £30k & E50k & \\
\hline Mean award, Small Claims scheme (£k) & 3.64 & 7.75 & 10.69 & $\begin{array}{l}\text { CNST/ELS* paid claims distribution, } \\
\text { adjusted for savings \& opting out }\end{array}$ \\
\hline Mean award for those using tort (£k) & 128.49 & 228.37 & 316.97 & CNST/ELS paid claims distribution \\
\hline $\begin{array}{l}\text { Proportion of paid claims under } \\
\text { threshold }\end{array}$ & 0.447 & 0.71 & 0.801 & CNST/ELS paid claims distribution \\
\hline Mean cost of Small Claims cases (£k) & 2 & 2 & 2 & Department of Health \\
\hline $\begin{array}{l}\text { Mean combined cost for those using tort } \\
\text { (over threshold) ( } £ \mathrm{k} \text { ) }\end{array}$ & 28.35 & 38.07 & 45.67 & CNST/ELS paid claims distribution \\
\hline $\begin{array}{l}\text { Mean combined cost for those using tort } \\
\text { (under threshold) ( } £ \mathrm{k} \text { ) }\end{array}$ & 7.19 & 10.89 & 12.18 & CNST/ELS paid claims distribution \\
\hline Increase in Small Claims cases (\%) & 80 & 80 & 80 & $\begin{array}{l}\text { MORI survey: proportion currrently } \\
\text { deterred by complexity and cost }\end{array}$ \\
\hline $\begin{array}{l}\text { Percent of Small Claims cases who seek } \\
\text { legal advice }\end{array}$ & 0.24 & 0.24 & 0.24 & $\begin{array}{l}\text { Assumption, equals } 1.2 \times \text { number } \\
\text { who appeal }\end{array}$ \\
\hline Cost of legal advice if sought ( $£$ k) & 1.5 & 1.5 & 1.5 & $\begin{array}{l}\text { Department of Health, based on } 10 \\
\text { hour fixed fee contract with claimant } \\
\text { solicitors firm }\end{array}$ \\
\hline $\begin{array}{l}\text { Percent of Small Claims cases who } \\
\text { appeal }\end{array}$ & 0.2 & 0.2 & 0.2 & Department of Health \\
\hline Cost of administering an appeal (£k) & 0.7 & 0.7 & 0.7 & $\begin{array}{l}\text { Department of Health, } £ 700 \text { from } \\
\text { Criminal Injuries Compensation } \\
\text { Appeals Panel }\end{array}$ \\
\hline
\end{tabular}

* Clinical Negligence Scheme for Trusts / Existing Liabilities Scheme

Table 4: Simulated cost of Swedish style no-fault scheme in England

\begin{tabular}{lc}
\hline Item & Cost £'000s (2001) \\
\cline { 2 - 2 } Annual total awards to claimants & $£ 1,919,263$ \\
Annual total costs of administration & $£ 167,036$ \\
Annual total cost of scheme & $£ 2,086,300$ \\
\hline
\end{tabular}


The total cost is estimated to be approximately £2.1bn per annum. This is over six times the estimated current cost of fault-based compensation to the NHS in England, as set out in Section 3 above. ${ }^{28}$ This estimated total cost is likely to be sensitive to a number of parameters, in particular, the generosity of awards, the proportion of preventable adverse events for which a claim is made, and the mean cost of administering each claim. If the mean award is assumed to be $£ 36,000$ (i.e. $50 \%$ of the current mean tort award), the total annual cost of the scheme falls to $£ 1.4 \mathrm{bn}$, compared with $£ 2.7 \mathrm{bn}$ when the mean award is $£ 73,000$ (i.e. unchanged from the current mean tort award). When the proportion of preventable adverse events for which a claim is made falls to $10 \%$, the total annual cost of the scheme falls to $£ 1.1 \mathrm{bn}$, compared with £3.8bn when 35\% of adverse events result in a claim. Finally, when the mean cost of administering each claim is reduced to $£ 300$, the total annual cost of the scheme is estimated to be $£ 1.9 \mathrm{bn}$, compared with $£ 2.3 \mathrm{bn}$ when the cost of administration rises to $£ 4,100$ per case.

In light of the high cost of all variants of a Swedish-style no-fault compensation scheme, we next examine the estimated costs of a small claims scheme, as outlined above, at varying ceiling values defining eligibility.

Table 5 shows that the total cost of the small claims scheme alone would vary between $£ 48 \mathrm{~m}$ and $£ 158 \mathrm{~m}$ per annum, depending on the threshold chosen for the scheme. The current suggestion in DoH (2003) consultation document is for a scheme with a ceiling of $£ 30,000$, which we estimate would cost in the region of $£ 116 \mathrm{~m}$. Of course, some of this cost can be offset against reductions in the number of claims settled under tort. In the simulation the cost of cases going to tort falls from $£ 450 \mathrm{~m}$ to $£ 374 \mathrm{~m}$ as the ceiling increases from $£ 10,000$ to $£ 50,000 .^{29}$ The combined cost of compensating patients is therefore estimated to be between $£ 498 \mathrm{~m}$ and $£ 533 \mathrm{~m}$, depending on the ceiling chosen. For a ceiling of $£ 30,000$, our estimate of the

\footnotetext{
${ }^{28}$ This comparison is approximate in the sense that the current cash cost of clinical negligence is a reflection of past events, whereas the estimate we have made for a no-fault scheme assumes the immediate settlement of claims from current events.

${ }^{29}$ Note that the estimates for tort payments are based on assumptions about the current rate of new litigation, and assume all claims are settled immediately, for comparability with the small claim simulations. In the absence of any small claims scheme, these assumptions lead to 5,192 paid tort claims per year at a cost of $£ 476 \mathrm{~m}$. Consequently these estimates are not directly comparable with the
} 
combined annual cost is $£ 518 \mathrm{~m}$ compared with $£ 476 \mathrm{~m}$ for tort calculated on an equivalent basis (see footnote 30 ) - an additional annual cost of $£ 42 \mathrm{~m} .^{30}$

Table 5: Simulated annual throughput and costs of a'small claims' scheme defined by different ceiling values

\begin{tabular}{llccc}
\hline & & \multicolumn{3}{c}{ Ceiling values for small claims: } \\
\cline { 3 - 4 } & & $£ 10,000$ & $£ 30,000$ & $£ 50,000$ \\
\hline $\begin{array}{llcc}\text { Costs within small } \\
\text { claims scheme }\end{array}$ & Claims paid (no.) & 4,177 & 6,635 & 7,485 \\
& Awards £’000 & 15,189 & 51,421 & 80,006 \\
& Costs £’000 & 33,177 & 64,998 & 78,146 \\
& Total £’000 & 48,366 & 116,419 & 158,151 \\
Costs of cases & Claims paid (no.) & 2,871 & 1,506 & 1,033 \\
using tort system & Awards £’000 & 368,887 & 343,824 & 327,469 \\
& Costs £’000 & 81,400 & 57,317 & 47,188 \\
& Total £’000 & 450,287 & 401,141 & 374,657 \\
Combined cost of & Overall cost £’000 & $\mathbf{4 9 8 , 6 5 3}$ & $\mathbf{5 1 7 , 5 6 0}$ & $\mathbf{5 3 2 , 8 0 9}$ \\
scheme & & & & \\
\hline
\end{tabular}

\section{CONCLUSIONS}

The origins of the research reported in this paper lie in dissatisfaction expressed in many quarters about the performance of the current system in England by which patients are compensated for injuries related to their medical care. The system is said to be costly and time-consuming because of the need to prove fault, with the consequence that too few patients obtain compensation for their losses. In spite of this barrier to claiming, clinicians are accused of taking excessive care ('defensive medicine') and being unwilling to report mistakes for fear of being sued. Consequently, the Department of Health has proposed reforms that diminish (without removing) fault as the basis for compensation, and allow access to 'fast-track', low-

current cash cost of tort claims incurred by the NHS as presented in Section 3.2 above, derived from NHSLA payments.

30 Once again, we would expect these estimates to vary depending on the precise values of administration costs, claims volumes in the presence of an 'easier' compensation scheme, reductions in award levels and tort leakage rates. 
cost determination of eligibility and benefits for claims of relatively low value ( $\mathrm{DoH}$, 2003). Our purpose here has been to summarise the key conceptual issues behind these policy choices, to review the evidence from both the UK and abroad, and to estimate the likely impact of a relevant range of policy options.

We have argued that a system which holds clinicians legally responsible for patients' injury costs makes very little sense as a pure compensation mechanism. The combination of legal process and liability insurance seems excessively cumbersome as a means of simply transferring funds between parties. Instead, the link between those responsible for an injury, and the amount of compensation paid, serves to place incentives appropriately, whether liability is based on fault or causation only. The key feature is the direct financial cost faced by the clinician or hospital from each mistake made, and this link can be a part of any well-designed compensation scheme, where the first payer is the agent best placed to take care. Any risk pooling the agent undertakes will also be incentive-compatible. We have referred to some evidence that the current English system of hospital-based liability has an impact on risk management behaviour by hospitals, but that this is in danger of being diluted through a recent reduction in cost-sharing measures.

If a comprehensive no-fault scheme along Swedish lines were to be introduced in England, we have estimated that the cost to the NHS would be several times the cost of the current system, due to a much increased number of claimants. It therefore seems more likely that concern about the overall cost of reform will result in a limited adoption of no-fault compensation for birth-related injuries, in addition to the retention of fault within some streamlined administrative scheme for low value cases with a view to increasing access and improving administrative efficiency simultaneously - the preferred option in DoH (2003). We have presented a set of estimates for the cost of such a scheme depending on the threshold used to define a 'small value' claim. These estimates suggest that such a scheme could potentially offer more rapid compensation to larger numbers of claimants than at present at an increase in annual total cost in the region of $£ 42 \mathrm{~m}$ (given the assumptions needed for comparability). This relatively modest figure assumes the retention of fault and does not include the additional cost of a no-fault scheme for birth-related injuries. In both this and the small value scheme, the ultimate cost to the NHS will depend on the 
administrative determination of liability; if the need to establish fault or causation is weakened, there is a large number of patients with potential claims under either scheme. The social efficiency of these proposed reforms will of course depend on how they are implemented; increasing numbers of valid claims arising from clinical errors are potentially valuable signals, and providing they are used effectively as such, there could be benefits to patient safety alongside wider access to compensation. 


\section{REFERENCES}

Bovbjerg, R. R., Sloan, F. A. \& Rankin, P. J. (1997): “Administrative performance of “no-fault” compensation for medical injury”, Law and Contemporary Problems, 60: $71-115$.

Cummins, J. D., Weiss, M. A. \& Phillips, R. D. (2001): “The incentive effects of nofault automobile insurance”, Journal of Law and Economics, 44(2): 427-464.

Danzon, P. M. (2000a): “Liability reform: Traditional and radical alternatives”, American Health Care: Government, Market Processes and the Public Interest, edited by R. D. Feldman, The Independent Institute: California.

Danzon, P. M. (2000b): “Liability for medical malpractice”, Handbook of Health Economics, Volume 1B, edited by A. J. Culyer and J. P. Newhouse, Elsevier North Holland: Amsterdam.

DoH (2003): “Making Amends: A consultation paper setting out proposals for reforming the approach to clinical negligence in the NHS. A report by the Chief Medical Officer”, Department of Health: London.

Fenn, P, Diacon, S., Gray, A., Hodges, R. \&. Rickman, N. (2000): “Current cost of medical negligence in NHS hospitals: Analysis of claims database”, British Medical Journal, 320: 1567-1571.

Fenn, P, Hermans, D. \& Dingwall, R. (1994): "Estimating the Cost of Compensating Victims of Medical Negligence”, British Medical Journal, 309: 389-91.

Fenn, P., Gray, A., Rickman, N., Diacon, S., Carrier, H. \& Young, R. (2002):

Evaluating Policy Alternatives for Patient Compensation: A Report to the Department of Health, November. 
Fenn, P., Gray, A. \& Rickman, N. (2003): “Liability Insurance, Deductibles and Hospital Risk Management: UK Evidence.”, Mimeo, University of Nottingham Business School.

Kennedy, I. (2001): The Report of the Inquiry into the Care and Management of Children Receiving Complex Heart Treatment between 1984 and 1995, 18 July, HMSO: London.

Lewis, R., McNabb, R., Robinson, H. \& Wass, V. (2003): “Loss of Earnings Following Personal Injury: Do the Courts Adequately Compensate Injured People?”, Economic Journal, 113: F568-F584.

Miceli, T. J. (1997): Economics of the Law, OUP: Oxford.

NAO (2001): Handling Clinical Negligence Claims in England, National Audit Office Report HC 403 2000-2001, 2 May; London.

NZBR (1998): Accident Compensation: Options for Reform, New Zealand Business Roundtable Wellington, New Zealand; September.

PAC (2002): Handling Clinical Negligence Claims in England, House of Commons Public Accounts Committee, 37 ${ }^{\text {th }}$ Report of Session 2001-02, HC 280.

Paterson, R. (2001): “The public's hue and cry: Medical complaints in New Zealand”, Journal of Health Services Research and Policy, 6: 193-194.

Sloan, F. A., Whetten-Goldstein, K., Entman, S. S., Kulas, E. D. \& Stout, E. M. (1997): "The road medical injury to claims resolution: How no-fault and tort differ”, Law and Contemporary Problems, 60: 35-70.

Studdert, D. M., Thomas, E. J., Zbar, B. I. W., Newhouse, J. P., Weiler, P. C., Bayuk, J. \& Brennan, T. A. (1997): “Can the United States afford a 'no-fault' system of compensation for medical injury?”, Law and Contemporary Problems, 60: 1—34. 
Studdert, D.M. \& Brennan, T. A. (2001): "No-fault compensation for medical injuries: The prospect for error prevention”, Journal of the American Medical Association, 286(2): 217-223.

Towse, A. \& P. Danzon (1998): “Medical negligence and the NHS: An economic analysis”, Health Economics, 8: 93-101.

Vincent, C., G. Neale \& M. Woloshynowych (2001): “Adverse events in British hospitals: Preliminary retrospective record review”, British Medical Journal, 322: $517-519$.

Weiler, P. C. (1991): Medical Malpractice on Trial, Harvard University Press: Cambridge, MA. 